\title{
Diplomasi Soft Power Indonesia melalui Atase Pendidikan dan Kebudayaan
}

\author{
Sartika Soesilowati \\ Departemen Hubungan Internasional Universitas Airlangga
}

\begin{abstract}
ABSTRAK
Studi ini membahas implementasi diplomasi Soft Power Indonesia melalui pertukaran dan pengembangan pendidikan dan kebudayaan di luar negeri. Bagaimana sebenarnya strategi dan karakter diplomasi ini? Sampai seberapa jauh diplomasi pendidikan memperkuat tujuan dan kepentingan nasional? Apa saja upaya, tantangan dan kesempatan dalam mengimplementasikan tipe diplo-masi ini? Studi ini menguatkan argumen bahwa ada hubungan secara langsung atau tidak langsung antara diplomasi pendidikan dan kepentingan nasional. Disamping beberapa beberapa capaian, masih ada beberapa kekurangan, dan kendala yang menghambat untuk dapat memaksimalkan hasil dari upaya pertukaran pendidikan internasional ini. Artikel ini juga berargumen bahwa diplomasi Soft Power memperkuat signifikansi 'new diplomacy' atau 'neo diplomacy'. Bentuk diplomasi ini melibatkan berbagai aktor sehingga bersifat inklusif dalam proses diplomasi saat ini dibutuhkan. Untuk menjelaskan secara lebih terperinci dari fenomena ini maka juga akan diterangkan dengan studi kasus atase Pendidikan dan Kebudayaan Indonesia di Filipina.
\end{abstract}

Kata-Kata Kunci: Soft Power, Diplomasi Pendidikan dan Kebudayaan, Atase.

This research discusses the implementation of Soft Power Diplomacy through international education exchange. How does actually the strategies and character of this diplomacy? To what extend does the educational diplo-macy enhance the national interest? What are the challenge, effort and oppor-tnity to implement this type of diplomacy? This study strengthens the argument that there is relations directly or indirectly between the implementation of educational diplomacy and the purpose of national interest. This article also argues that soft power diplomacy reinforces the significance of 'new diplomacy' or 'neo diplomacy'. This form of diplomacy involving various actors, and hence inclusiveness in the process of diplomacy is now needed. However, there are still some weakness and challenge that hamper to maximise the result. In order to explain more detailed this study conducts the case of Education and Cultural Attache of Indonesia in Manila, Philippines.

Keywords: Education, Soft Power Diplomacy, Attache. 
Diplomasi adalah salah satu cara untuk meraih kepentingan nasional. Melalui diplomasi Soft Power khususnya di bidang pendidikan dan kebudayaan, kepentingan nasional dalam memperkuat kredibilitas RI diluar negeri dan peningkatan sumber daya manusia dapat tercapai. Tujuan peningkatan sumber daya manusia ini telah tercantum antara lain dalam Rencana Pembangunan Jangka Panjang Nasional (RPJPN 2005 - 2025). Secara lebih spesifik di dalam Rencana Pembangunan Jangka Menengah RPJM tahun 2015-2019 menyatakan: "Memantapkan pembangunan secara menyeluruh dengan menekankan pembangunan keunggulan kompetitif perekonomian yang berbasis SDA yang tersedia, SDM yang berkualitas, serta kemampuan IPTEK” (Kemdikbud 2014). Dalam kerangka ini maka diplomasi pendidikan menjadi salah satu strategi yang efektif dalam rangka membuka peluang untuk merealisir tujuan tersebut.

Mengacu pada tujuan tersebut selama beberapa tahun terakhir ini, pemerintah RI melalui Kementrian Pendidikan dan Kebudayaan (Kemdikbud) menjalankan berbagai kegiatan kerjasama luar negeri antara lain: 1) mengirimkan pelajar, mahasiswa, staf pengajar, tenaga pendidik Indonesia ke luar negeri; 2) meningkatkan pemberian beasiswa pada mahasiswa asing; 3) melakukan Memorandum of Understanding (MoU); 4) mengikutsertaan para pejabat tinggi dalam berbagai forum internasional dan pertemuan dengan pihak asing; 5) menggalang kerjasama dalam publikasi, riset dan alih tekhnologi; 6) pelatihan dan pendirian sekolah untuk WNI di luar negeri; serta 7) memfasilitasi pertukaran kurikulum, double degree dan sister city (Kemdikbud 2011). Untuk lebih memperkenalkan dan menguatkan pengaruh Indonesia di luar negeri Kemdikbud pada tahun 2013 membuka Rumah Budaya Indonesia di hampir 10 negara (Republika 2012). Aktivitas tersebut dilakukan dengan kesadaran untuk meningkatkan soft power.

Dalam menjalankan kebijakan tersebut Atase Pendidikan RI menjadi salah satu agen utama yaitu sebagai fasilitator, koordinator, dan server dalam menjalankan aktivitas diluar negeri. Untuk menunjang pelaksanaan diplomasi ini, pemerintah RI pada beberapa tahun terakhir juga telah menambah jumlah Atase Pendidikan dari 16 Atase yang sudah ada. Tahun 2013, misalnya, dibuka perwakilan Atase Pendidikan di Singapura, dan India guna mengantisipasi perkembangan yang ada. Pemerintah juga berupaya membuka Atase Pendidikan di negara yang berminat menjalin hubungan bilateral yang lebih dekat, seperti Korea Selatan. Penguatan dan perluasan fungsi Atase Pendidikan RI ini sesungguhnya menandai telah terjadi upaya penguatan neo-diplomacy atau diplomasi yang dilakukan oleh people to people, untuk membedakannya dari diplomasi klasik yang hanya melibatkan elit negara. 
Berbagai aktivitas yang terkait dengan diplomasi pendidikan dan upaya meningkatkan soft power RI ini menggiring pada pertanyaan: Apa yang bisa dimaknai dari strategi diplomasi RI yang dikategorikan sebagai soft power yang sedang dilakukan ini? Seberapa jauh diplomasi pendidikan dan budaya yang dikategorikan sebagai soft power ini dapat merealisasi tujuan nasional khususnya dalam meningkatkan sumber daya manusia Indonesia dan lebih luas lagi pengaruh Indonesia di luar negeri? Apa saja kendala, upaya dan peluang untuk menjalankan diplomasi ini?

Studi ini berpendapat bahwa upaya kerjasama keluar negeri tersebut bisa dimaknai sebagai suatu aktivitas Diplomasi Soft Power untuk mencapai tujuan nasional seperti memperkuat pendidikan dan keahlian bangsa dan meningkatkan kredibilitas Indonesia di luar negeri. Meski tidak dapat dipungkiri, ada beberapa kelemahan dan hambatan dalam pelaksanaannya. Untuk menunjang argumentasi secara detail, maka diterangkan melalui studi kasus Atase Pendidikan dan Kebudayaan Kedutaan Besar Republik Indoneisa (KBRI) di Manila, Filipina. Diawali dengan mengulas perdebatan teoritis dan empiris tentang Soft Power, dilanjutkan dengan menjelaskan signifikansi dan tujuan diplomasi pendidikan/kebudayaan RI, kemudian menguraikan kepentingan nasional RI di Filipina beserta pelaksanaan diplomasi pendidikan dan kebudayaan yang dijalankan Atase di Manila.

\section{Diplomasi Soft Power: Tinjauan Karakter dan Signifikansi}

Pembahasan tentang definisi dan makna dari diplomasi secara umum seringkali dikaitkan dengan proses, aktivitas, dan negosiasi yang dilakukan secara damai oleh suatu negara dalam menjalin hubungannya dengan negara lain dengan maksud untuk mencapai tujuan nasionalnya. "Diplomacy is peaceable coercion to promote the interest of the state and nation" (Freeman 2006, 72). Diplomasi adalah suatu cara berhubungan antara negara yang tidak dilakukan dengan perang dalam mempromosikan kepentingan negara. Diplomasi juga bermakna mempertemukan kepentingan yang berbeda diantara negara. Hedley Bull (1997, 117) menyatakan bahwa diplomasi adalah "states have different interest, and ... common interests have first to be identified by process of bargaining before any question of maximization of them can rise." Melalui diplomasi maka kepentingan yang berseberangan mudah diidentifikasikan dan sebaliknya kepentingan yang sama dapat dipertemukan sehingga terjalin kerjasama.

Meski relevansi diplomasi sudah jelas dalam menunjang kepentingan nasional di forum internasional, namun sesungguhnya dalam Ilmu Hubungan Internasional teorisasi diplomasi dianggap tidak sepenuhnya berkembang. Upaya melakukan generalisasi terhadap praktek diplomasi 
sulit dilakukan karena aktivitas diplomasi dianggap sangat bervariasi sekaligus paling tidak pasti dan sulit diprediksi (Steiner 2004, 493). Bahkan diantara berbagai aktivitas umat manusia "diplomacy is the most protean" (Nicholson di Olson 1994, 122 ). Terkait problematika ini maka adalah sangat signifikan untuk terus mengungkap variasi praktek diplomasi yang ada dan pengembangan teori ini khususnya seberapa jauh aktivitas diplomasi dapat mendukung kepentingan nasional.

Keberhasilan berdiplomasi ditentukan oleh dimensi kekuatan atau pengaruh yang dimiliki oleh negara yang dibedakan antara hard power dan soft power. hard power adalah kekuatan/pengaruh yang bersifat tangible seperti militer, geografi, dan ekonomi. Sedangkan soft power yang dipopulerkan Joseph Nye $(2004,256)$ bersumber pada "cultural attraction, ideology, and international institutions" dan diasumsikan sebagai "the ability of a state to get other countries to want what it wants" dan "ability to get what you want through attraction rather than coercion or payments." Cara diplomasi ini tidak memerlukan stick (paksaan) atau carrots (iming-iming) untuk menggerakkan seseorang menuruti arahan kita.

Membandingkan kedua tipe power tersebut, sesungguhnya unsur hard power relatif mudah untuk diidentifikasi dan diukur. Soft Power memiliki bentuk, dan kharakter yang 'uncontrollable" dan "unpredictable" (Fan 2007, 147) Memprediksi sekaligus mentarget hasil dari diplomasi soft power menjadi hal yang tidak mudah karena sifatnya yang intangible dan melibatkan masyarakat luas. Yang menarik, meski kesulitan tersebut jelas namun kecenderungan saat ini menunjukkan bahwa negara-negara di dunia berupaya untuk mengembangkan Soft Power secara lebih intensif. Amerika Serikat (AS) saat ini mendorong upaya perningkatan diplomasi soft power. Hegemoni AS didunia diramalkan akan runtuh apabila AS tidak mengimplementasikan soft power secara signifikan (Nye 2004; Nye 2010). Pengakuan terhadap Tiongkok sebagai salah satu kekuatan ekonomi dunia dan dianggap pesaing dekat dari AS tidak lepas dari keberhasilan negara ini dalam mengelola diplomasi soft powernya. Strategi diplomasi Tiongkok yang disebut sebagai "charm offensive" dianggap lebih berhasil dalam melakukan pendekatan kepada negara-negara yang dituju daripada misalnya AS yang menjalankan diplomasi konvensionalnya (Kurlantzick 2007). Pemerintah Tiongkok piawai dalam menjual "attractiveness" Tiongkok melalui budaya, sejarah, nilai-nilai etos kerja, disamping secara simultan mengembangkan sumber daya keluar secara ekspansif di bidang pendidikan dan riset.

Salah satu negara di Asia yang saat ini dianggap 'The Rising Middle Power', India, juga yakin dengan keampuhan strategi soft power terkait nilai dan budaya dalam kebijakan luar negerinya. PM India Manmohan Singh menyatakan bahwa pada masa lalu India pernah menjadi 'global 
super power' dikarenakan kekuatan nilai dan ide budaya dan agama yang dimiliki oleh negara ini. Hal ini dilakukan tidak melalui upaya penaklukan berdarah (www.pmindia.nic.in). India menyatakan tekadnya untuk merevitalisasi kembali soft powernya guna meningkatkan posisinya di dunia. Bagi negara-negara dengan unsur kepemilikan hard power - nya relatif lemah, maka tumpuan untuk menggunakan soft power menjadi suatu hal yang rasional bila ingin berhasil dalam mempertahankan kepentingan nasionalnya dalam berdiplomasi. Khusus bagi Indonesia, pilihan penguatan diplomasi yang tidak bertumpu pada material sesungguhnya lebih bijak. Indonesia diyakini memiliki kekuatan nasional yang berdimensi hard power yang kuat namun tidak ditunjang kualitas. Pada tahun 2014 jumlah penduduk Indonesia 240 juta jiwa dan merupakan penduduk terbesar ke empat di dunia. Negara ini juga memiliki kepulauan terbesar didunia dengan luas wilayah 1,9 juta $\mathrm{km}$ persegi dengan 17.000 pulau, dan meluas 7,9 juta $\mathrm{km}$ persegi ZEE. Ditambah posisi geostrategis dan potensi alam yang luar biasa yang terkandung di bumi Indonesia. Kondisi geografis ini bisa diartikan bahwa sesungguhnya Indonesia berpotensi mempunyai status sebagai pemimpin regional atau global yang ditunjukkan oleh "has hitherto been determined by its large population, geographical position and its economic" (Smith 2000, 9).

Namun sayangnya kondisi fisik ini belum bisa diandalkan menjadi suatu kekuatan hard power. Human Index Development (HID) Indonesia pada tahun 2014 masih dikategorikan medium ranking 108 diantara 187 negara di dunia (UNDP 2014). Meski Indonesia memiliki potensi kepulauan dan kelautan yang luar biasa tapi potensi kelautan yang semestinya menjadi andalan Indonesia di peta dunia terabaikan. Salah satu solusi untuk menyiasati kelemahan ini maka Indonesia harus mampu mempopulerkan 'attractiveness' atau faktor yang membuat Indonesia menarik dimata negara lain. Tumpuan untuk menjalankan diplomasi soft power saat ini adalah sesuai dengan karakter dan kapabilitas RI yang diakui mempunyai modal budaya yang kuat, sistem politik demokrasi, Islam yang moderat dan negara berhaluan politik bebas aktif. Tujuan diplomasi soft power adalah untuk meningkatkan pembangunan nasional, dan lebih spesifik lagi bila dikaitkan dengan pendidikan berarti meningkatkan daya saing (Tatar 210, 47). Termasuk disini adalah meraih simpati, pengaruh terhadap negara lain.

\section{Tujuan dan Peluang Diplomasi Pendidikan dan Budaya Indonesia}

Berbagai aktivitas yang terkait dengan luar negeri yang dilaksanakan oleh Kemdikbud dapat dimaknai sebagai suatu bentuk diplomasi dalam upaya untuk mencapai tujuan kebijakan nasional. Perhatian utama ditujukan kepada Pendidikan karena 'pendidikan adalah sesungguhnya 
dimensi utama dari diplomasi budaya' (Asia Pulse 2011). Dampak yang diharapkan dari diplomasi budaya dan pendidikan ini secara langsung adalah melakukan internasionalisasi pendidikan yaitu mengejar ketertinggalannya dalam riset dan pendidikan dan mentransformasikan bangsa Indonesia mampu melakukan aktivitas dalam bidang riset dan pendidikan setara dengan lembaga pendidikan di luar negeri yang telah mapan.

Tujuan dari diplomasi pendidikan saat ini juga terkait dengan pertimbangan prioritas nasional Indonesia untuk mengembangkan sumber daya manusia melalui pendidikan terkait dengan tantangan nasional yang dihadapi oleh bangsa Indonesia. Mulai tahun 2015, ASEAN Community mulai diberlakukan yang berarti akan terjadi persaingan yang lebih kompetitif dalam pasar tenaga kerja. Indonesia sangat berkepentingan untuk dapat bersaing dan memanfaatkan kemudahan yang terjadi dengan diberlakukannya ASEAN Community. Apalagi pada tahun 2020 - 2030 Indonesia diperkirakan akan menikmati yang disebut bonus demografi (BKKBN 2014). Tenaga pada umur produktif melebihi dari yang tidak produktif yang berarti ada peluang menikmati kesejahteraan. Namun peluang tersebut tidak akan diraih apabila sumber daya manusia Indonesia tidak mampu berkompetisi dengan negara lain baik dalam mengelola kekayaan dalam negeri maupun meraih kesempatan diluar negeri. Oleh karenanya peningkatan sumber daya manusia yang kompetitif di tingkat regional dan global adalah faktor yang sangat penting. Pendidikan, dan pelatihan serta transfer pengetahuan dan tekhnologi menjadi cara yang paling efektif untuk mempercepat peningkatan sumber daya manusia Indonesia.

Sebagaimana Amartya Sen $(2002,2)$ telah menyatakan bahwa pendidikan adalah penting bagi pengembangan human capability yang diperlukan untuk meningkatkan human security agar mampu bersaing dalam kompetisi global. Karena melalui pendidikan akan terbuka akses dan kesempatan untuk meningkatkan kemampuan bangsa ditingkat global sekaligus memenangkan persaingan dan berujung pada kesejahteraan dan kemakmuran masyarakat. Terlebih, diplomasi budaya ini diperlukan untuk meningkatkan hubungan antar bangsa secara kuat. Diplomasi pendidikan dan budaya diyakini akan meningkatkan 'mutual understanding, mutual interest, mutual respect dan mutual trust' (Asia Pulse 2011) antar kedua belah pihak. Diplomasi ini merupakan suatu strategi yang efektif dalam upaya menumbuhkan saling perhatian dan kepentingan bersama. Hal ini disebabkan salah satunya karena diplomasi budaya dan pendidikan akan memberikan efek positif dalam merengkuh 'Heart and Mind' suatu bangsa (Nye 2004). Signifikansi diplomasi budaya yang mempunyai kharakter kuat sebagai suatu diplomasi publik ini sesunguhnya akan melengkapi diplomasi yang 
bertipe formal, klasik atau elitis yang biasanya berkaitan dengan isu politik, dan keamanan. Tipe-tipe diplomasi seperti ini seringkali tidak menyentuh secara langsung hubungan dan kebutuhan masyarakat di kedua negara.

\section{Kepentingan Nasional RI terhadap Filipina}

Terdapat berbagai pertimbangan strategis dan praktis untuk memperkuat kerjasama pendidikan dengan Filipina. Pertama adalah dikaitkan dengan tujuan untuk memperdalam hubungan bilateral. Meski hubungan antara Indonesia Filipina telah berjalan selama lebih dari setengah abad yang berupa The Treaty of Frienship (1951-2011), bekerjasama dalam ASEAN sejak 1967, namun sampai tahun 2011 kedua negara belum mempunyai Memorandum of Understanding (MoU) dalam bidang pendidikan. Artinya "kerjasama kedua negara belum mempunyai payung kerjasama kedua pemerintahan" (Atdikbud Manila 2014). Berarti hal ini juga bisa diartikan bahwa sesungguhnya diplomasi pendidikan di level first track diantara kedua negara perlu lebih diperkuat guna memberikan kemudahan bagi publik dikedua negara untuk melakukan kerjasamanya dan mengambil manfaat dari kerjasama tersebut.

Pertimbangan kedua adalah terkait dengan kepentingan Indonesia untuk memanfaatkan sistem pendidikan di Filipina. Sistem pendidikan di negara ini dianggap mempunyai reputasi yang baik di tingkat regional dan global. Filipina menjadi rujukan pendidikan berbagai kawasan. Atase Pendidikan (Atdik) RI di Manila menyatakan bahwa beberapa bidang ilmu di Filipina menjadi pilihan utama bagi mahasiswa asing, khususnya Indonesia seperti bisnis, kedokteran, keperawatan, akuntasi dan pendidikan pilot/penerbang dan sekolah pemeliharaan pesawat terbang. Pendidikan di Filipina juga umumnya dilaksanakan dengan bahasa Inggris yang bisa dimanfaatkan bagi pelajar Indonesia yang membutuhkan peningkatan bahasa Inggris.

Minat untuk membuka kerjasama pendidikan dengan mengirimkan mahasiswa Indonesia ke Filipina didasari oleh beberapa alasan praktis dan efisiensi. Salah satunya adalah pertimbangan biaya yang cukup murah disamping kedekatan wilayah. Contohnya biaya pendidikan kedokteran (Medical Doctor/setara magister kedokteran) di Filipina biayanya rata-rata $\$ 700-1000$ per semester; Sekolah pilot di Filipina tarifnya 50-60 \% dari biaya sekolah pilot di Indonesia dan dapat ditempuh dalam jangka waktu 12-18 bulan sedang di Indonesia 24-36 bulan. Dengan biaya pendidikan yang murah, dan relatif cepat lulus, hal ini menjanjikan untuk mempercepat ketersediaan sumber daya pilot yang sangat dibutuhkan oleh Indonesia saat ini. Kredibilitas kemampuan pilot Filipina dikenal di dunia karena ditunjang oleh 
kondisi topografi Filipina. Mereka handal karena sudah terbiasa berlatih menyesuaikan kondisi alam Filipina yang relatif sulit.

Pertimbangan berikutnya bagi Indonesia akan pentingnya untuk mengirimkan siswanya dan melakukan kerjasama di bidang pendidikan adalah diakuinya reputasi lulusan dari Filipina. Misalnya, lulusan keperawatan dari negara ini dikenal mempunyai reputasi global yaitu dapat diterima bekerja di hampir semua negara didunia. Hal ini dikarenakan pendidikan keperawatan dan farmasi di Filipina mempunyai system board exam yang sangat bagus. Hal seperti ini yang ingin ditiru dan dipelajari oleh Indonesia dengan kerjasamanya. Dari kenyataan ini, Indonesia dapat mengambil manfaat dari MoU untuk meningkatkan kemampuan sumber daya manusia khususnya dalam hal keperawatan yang saat ini banyak dibutuhkan di level nasional dan internasional. Demikian juga dengan bidang pertanian, sudah lama Filipina diakui memiliki institusi riset yang menonjol dan diakui dunia dalam bidang ini. Pendidikan pertanian adalah salah satu bidang yang sudah lama menjadi favorit bagi mahasiswa Indonesia di Filipina. Apalagi saat sekarang dengan isu ketahanan pangan global, maka dibutuhkan ahli-ahli pangan yang bisa membantu mempercepat terwujudnya swasembada pangan di Indonesia sekaligus bersaing di level global seperti pengekspor komoditi pertanian. Dengan kesamaan topografi , bagi Indonesia belajar dari keunggulan Filipina di bidang pertanian ini akan lebih bermanfaat. Dibidang pengelolaan hasil perikanan, Indonesia yang masih ketinggalan dalam pengelolaan hasil perikanan berkepentingan belajar dari Filipina sebagai negara yang bereputasi dalam bidang ini dilevel global. Adalah suatu ironi bahwa Indonesia mempunyai wilayah laut yang luas dan sumber daya nelayan yang melimpah namun tidak mampu memaksimalkan pengelolaan komoditi perikanan. Dalam konteks tujuan nasional saat ini yang mengutamakan kebijakan kemaritiman nasional, maka upaya untuk meningkatkan sumber daya manusia Indonesia seperti peningkatan kemampuan pengelolaan perikanan adalah suatu hal yang krusial.

Banyak sektor lain juga bisa disebutkan menunjukkan ketertinggalan Indonesia dalam sumber daya manusia dibandingkan dengan Filipina. Tenaga kerja Filipina mendominasi lapangan kerja asing di Indonesia. Jauh lebih banyak tenaga kerja Filipina yang berkerja di Indonesia dibandingkan sebaliknya. Contohnya banyak tenaga kerja Filipina bekerja sebagai guru, khususnya bahasa Inggris di sekolah internasional di Indonesia. Para profesional Filipina juga terkenal handal bekerja diberbagai perusahaan swasta ataupun perusahaan multinasional di Indonesia, khususnya di Jakarta. Dengan masih banyaknya pengangguran di Indonesia, sementara warga asing seperti Filipina mendapatkan pekerjaan di Indonesia menimbulkan pertanyaan adalah mengapa bangsa Indonesia tidak bisa bersaing bagi pekerjaan ditanah air sendiri? Bagaimana pembinaan, pelatihan dan sistem pendidikan 
khususnya dibidang-bidang yang menunjukkan keunggulan sumber daya Filipina? Pertanyaan tersebut menggiring pada kebijakan dan aksi untuk untuk mengembangkan diplomasi pendidikan ketingkat yang lebih erat dengan maksud untuk belajar dari pengalaman profesional Filipina.

Indonesia juga berkepentingan agar proses perdamaian di Filipina, khususnya Mindanao terwujud. Konflik bersenjata di Mindanao Selatan antara pemerintah Filipina dengan kelompok MNLF, MILF atau Abu Sayaff belum berakhir. Gangguan keamanan masih menjadi perihal yang mengkhawatirkan bagi Indonesia. Duta Besar RI untuk Filipina, Johny Lumintang, menyatakan kecemasannya bahwa konlik semacam ini akan memberikan dampak terhadap situasi keamanan di wilayah Indonesia, khususnya yang berbatasan dengan Indonesia (wawancara July 2014). Kekhawatiran bahwa wilayah Indonesia akan menjadi basis pelatihan, perlindungan teroris, termasuk aksi teror bukan berlebihan mengingat kedekatan wilayah, dan situasi geografis serta sosial budaya masyarakat di wilayah yang rentan. Sejauh ini pemerintah Indonesia melalui persetujuan pihak yang bersengketa yaitu pemerintah Filipina dan MNLF/MILF terlibat dalam implementasi proses perdamaian. Indonesia berkepentingan untuk membantu proses ini terwujud.

\section{Pelaksanaan Diplomasi Soft Power Atdikbud}

Peran yang dilakukan oleh Atdikbud Filipina dalam menjalin hubungan di bidang pendidikan dan kebudayaan di luar negeri adalah salah satu contoh untuk menggambarkan pelaksanaan diplomasi soft power. Tugas dan kewajiban yang dilakukan Atase ini mempromosikan kebijakan negara sekaligus mempromosikan hubungan yang lebih baik dengan elit lokal (James 1980, 937). Atdikbud berfungsi sebagai sebagai ujung tombak sekaligus pelaksana riil dilapangan dalam menjalankan diplomasi soft power di negara yang menjadi wilayah akreditasinya. Diplomasi yang dilakukan oleh Atdikbud mempertimbangkan prioritas nasional Indonesia untuk mengembangkan sumber daya manusia melalui pendidikan. Hal ini demi kepentingan meningkatkan kompetisi Indonesia. Dalam melaksanakan diplomasi yang berjalan dua arah adalah penting bukan hanya berpijak pada pendekatan yang rasional tapi juga pendekatan yang mengutamakan common interest. Kepentingan nasional adalah yang utama, tapi kerjasama tersebut tidak akan berkesinambungan apabila pihak tuan rumah tidak mendapat keuntungan yang memadai.

Melalui cara-cara diplomasi soft power khususnya bidang Pendidikan dan Kebudayaan ini, diharapkan Indonesia akan memperoleh manfaat seperti: (1) Meningkatkan 'attractiveness' Indonesia, yaitu unsur-unsur 
yang akan meningkatkan ketertarikan dan kedekatan terhadap negara dan bangsa Indonesia; (2) Membuka peluang, mendapatkan dan memperluas kerjasama pendidikan dengan pihak luar; (3) Dari kerjasama tersebut diharapkan Indonesia akan mendapat bantuan untuk meningkatkan kualitas pendidikan. Ini akan memperkuat kapasitas sumber daya Indonesia agar mampu bersaing di tingkat global.

Atase Pendidikan dan kebudayaan RI di Manila mengelola kerjasama bilateral pendidikan dan kebudayaan dengan Filipina, Palau Republic dan Republic of Marshal Island. Dalam tugas, pelaksanaan dan fungsinya mengacu pada pengejawantahan dari Tripple Mission secara nasional yaitu Fungsi Administrasi dan Keprotokoleran, Fungsi Akademik dan Inteligent dan Fungsi Diplomasi dan Kerjasama. Pencapaian kerja Atdikbud di Manila kurun waktu tahun 2010 sampai 2013 secara garis besar adalah (1) Melaksanakan kerjasama MOU $G$ to $G$ dengan Filipina; (2) $G$ to $G$ dengan Palau dan Marshal; (3) Pertukaran pelajar, pertukaran program Madrasah, tenaga pengajar, admistrasi; (4) Pengiriman administrator, tenaga Pendidik/Kepala Sekolah, tenaga keperawatan untuk mengikuti training; (5) Pameran budaya dan tari traditional; (6) Pengembangan Madrasah School, sister school; (7) Implementasi MoU University to University; (8) Seminar dan Workshop internasional; (9) Pelatihan seni dan Bahasa Indonesia (10) Pembentukan Indonesia Center; (11) Beasiswa Unggulan bagi pelajar Indonesia untuk belajar di universitas di Filipina (Atdikbud Manila 2014, 20-21). Disamping itu Atase juga melakukan tugas khusus yaitu: (1) MOU Government to Government on Basic Education; (2) MOU University to University yang hasilnya berupa implementasi double degree/dual degree/joint degree dan sister school; pertukaran ahli, pertukaran mahasiswa, seminar/workshop internasional, dan pengembangan joint journal.; (3) Pendirian SMP terbuka di Tupi dan Leansasi, Mindano; (4) Pemberian 500 beasiswa untuk siswa WNI miskin di Mindano; (5) 25 beasiswa untuk guru di Mindanao.

Dalam menjalankan tugas dan kewajiban diatas maka Atdikbud di Filipina menjalankan misi diplomasinya secara bervariasi baik 'diplomasi klasik', dan 'neo diplomasi' secara simultan atau multi track. Atase dalam kenyataan menjalankan misi diplomasi di level 1 dengan pejabat tingkat atas, maupun di level pejabat eselon atau teknis sekaligus berbaur, berunding langsung dengan masyarakat khususnya mahasiswa, pelajar dan dunia pendidikan di Filipina. Misi tersebut diatas juga memberikan tugas dan tanggung jawab bagi Atdikbud untuk melakukan 'diplomasi dalam dan keluar'. Diplomasi kedalam berarti diplomasi yang dijalankan oleh seorang Atdikbud dapat meyakinkan para kolega serta pimpinan di lingkungan baik di Kemdikbud dan Kemenlu, khususnya KBRI Manila dan stake holder pendidikan di Indonesia akan pentingnya program kerjasama dan pendidikan yang dilakukannya di luar negeri. Ke pihak luar maka tugas Atdikbud adalah 
melakukan diplomasi kepada pihak diwilayah tugas di luar negeri yang telah ditentukan. Tugas ini termasuk membuka, mempelopori, menjadi ujung tombak dan fasilitator dalam pelaksanaan kerjasama dengan pihak terkait di wilayah akreditasi Atdikbud.

Dalam konteks pemaknaan strategis, beberapa kebijakan dan pelaksanaan tugas Atase tersebut dimaksudkan untuk secara umum meningkatkan hubungan kedua negara dan khususnya pengaruh Indonesia terhadap Filipina. Atdikbud mempresentasikan yang disebut sebagai "attractiveness" Indonesia lewat budaya terhadap masyarakat Filipina. Contohnya adalah pameran Budaya dan tari tradisional Indonesia, pelatihan seni dan budaya Indonesia (sekitar 42 siswa Filipina), pelatihan Bahasa Indonesia, serta pengembangkan bahasa dan budaya Indonesia di Indonesia Center di University of Philippines, University of Santo Tomas, Miriam College dan Arellano University. Disamping itu juga dibentuk wadah SAHABAT INDONESIA (Atase Pendidikan KBRI Manila, 2014). Institusi semacam ini memberi wadah bagi keterikatan dan simpati masyarakat Filipina terhadap Indonesia atau membuka "hati dan pikiran'. Di lingkup yang lebih luas, kerjasama antar pendidikan tinggi dan pembukaan berbagai pusat bahasa dan budaya diberbagai universitas di Filipina bermakna bahwa Indonesia bermaksud untuk tidak hanya sebatas memperkenalkan juga lebih mendekatkan sosok Indonesia terhadap publik Filipina. Pembukaan pusat seni dan budaya ini juga bisa diartikan sebagai bentuk upaya untuk memperkuat ASEAN Social and Cultural Community. Karena sesungguhnya pilar dari ASEAN Community terletak pada hubungan bilateral yang kuat. Di lingkup internasional, ini berarti bahwa Indonesia menunjukkan bukti dan upaya penguatan strategi diplomasi soft powernya yaitu dengan mempromosikan segi "attractiveness".

Dalam pelaksanaan kerjasama pendidikan dilevel perguruan tinggi, sejauh ini MoU perguruan tinggi belum final. Meski demikian implementasi kerjasama telah dilakukan melalui program $\mathrm{U}$ to $\mathrm{U}$ collaboration (UtoU). Contohnya yang sudah ada meliputi: (1) pertukaran dosen dan mahasiwa a.l antara UI dengan University of Philipines dan Santo Thomas; (2) joint degree dan credit transfer; (3) joint research, (4) expert exchange (5) seminar, workshop dan pertemuan ilmiah. Kerjasama antar universitas Filipina dan Indonesia semacam ini akan dapat meningkatkan performance Indonesia di level regional dan internasional. Indonesia harus diakui masih kurang dalam publikasi internasional, penelitian dan kerjasama internasional bahkan di level regional. Serangkaian kegiatan diplomasi pendidikan yang telah dilakukan dalam kurun waktu 2011 - 2013 juga menunjukkan ada korelasi yang kuat antara kebijakan pendidikan dan kebudayaan dengan kepentingan nasional RI. Ada upaya untuk mensinergikan antara kebutuhan peningkatan sumber daya manusia di Indonesia melalui pemberian beasiswa untuk bidang-bidang yang Indonesia masih relatif 
lemah semisal keperawatan, pertanian dan perikanan. Pilihan prioritas untuk kerjasama melalui pengiriman mahasiswa di bidang-bidang ilmu semacam keperawatan di Filipina didasarkan pada pertimbangan bahwa tenaga keperawatan Indonesia belum diakui secara internasional sebagaimana Filipina. Indonesia perlu belajar dari Filipina untuk meningkatkan daya saing. Ini mencerminkan manfaat dan hakikat dari diplomasi yang pada tujuan akhirnya dimaksudkan untuk meningkatkan kekuatan nasional.

Strategi pemerintah Indonesia untuk mendekatkan Indonesia ke masyarakat Filipina juga memiliki kepentingan politis kuat. Sebagai ilustrasi, Pemerintah RI melalui Atdikbud mendirikan SMP terbuka di Tupi dan Laensasi, Mindanao pada 2012 dan memberikan beasiwa untuk 500 anak miskin di Filipina. Pilihan terhadap mereka bukan tanpa alasan khusus. Para siswa tersebut termasuk dari sekitar 15002000 anak dibawah usia sekolah dari WNI/keturunan WNI yang dikategorikan sebagai undocumented (Atase Pendidikan KBRI Manila, 2014). Adalah tidak bisa diragukan bahwa kebijakan seperti ini adalah perlu dalam kerangka tanggung jawab pemerintah RI akan perlindungan dan jaminan terhadap warga negara sesuai UUD 45 khususnya pemenuhan Hak-hak Konstitusi warga negara dalam hal pendidikan dan tempat tinggal. Kebijakan ini menunjukkan bahwa negara tidak mengabaikan nasib warga negaranya. Terlebih lagi wilayah dengan penduduk undocumented rawan dalam segi keamanan. Mereka adalah obyek yang mudah digunakan untuk kejahatan trafficking dan terorisme. Pendekatan dengan mendirikan sekolah bagi anak-anak serta identifikasi status kependudukan adalah langkah awal untuk mendeteksi dan menghindarkan ancaman keamanan tersebut.

Pemberian beasiswa kepada para guru dan pengembang madrasah di wilayah Mindano juga mempunyai kepentingan strategis. Pada tahun 2011/2012 diberikan 25 beasiswa, dan 2013 sebanyak 40 beasiswa s2 dan s3 juga pemberian bea siswa Darmasiswa sejumlah 10 orang pada 2011/2012, dan 7 pada 2013. (Atase Pendidikan KBRI Manila 2014, 25). Para guru tersebut dikirim belajar ke beberapa Universitas di Indonesia. Mindano adalah wilayah konflik paling berdekatan dengan Indonesia dan penduduknya memeluk agama Islam. Pemberian beasiswa ini sebagai suatu strategi untuk tidak hanya meningkatkan kapasitas para guru di Mindano juga sebagai upaya Indonesia dalam kontribusinya untuk Peace Making dikawasan ini. Seperti yang diungkapkan oleh kedua nara sumber, yaitu Duta Besar Indoneisa untuk Filipina, Johny Lumintang dan Atase Pendidikan KBRI Manila Ibu Paristyanti Nurwandani bahwa pemberian beasiswa ini diberikan dengan misi antara lain "meningkatkan pengetahuan Islam yang lebih moderat seperti yang sudah diterapkan Indonesia". Dengan kata lain beasiswa ini dimaksudkan menjadi agent of change atau agent of transform untuk turut membentuk masyarakat/pemerintahan moderat Islam. Bagi 
Indonesia adalah penting untuk mempunyai kawasan/pulau perbatasan seperti Mindanao dalam kondisi aman. Seperti diungkapkan oleh Atase Pertahanan Indonesia di Filipina bahwa adalah penting bagi Indonesia untuk membantu pemerintah Filipina menjadikan wilayah Mindanao sebuah kawasan yang tidak akan menjadi sarang pelarian, dan pelatihan bagi kelompok ekstrimis dan teroris. Hal ini dikhawatirkan menjadi ancaman keamanan bagi kawasan Indonesia lain.

\section{Tantangan Diplomasi oleh Atdikbud}

Terdapat beberapa kendala dalam pelaksanaan Diplomasi soft power RI khususnya yang dilakukan oleh Atdikbud meliputi: nature kerjasama, masalah keuangan, adminsitratif, dan kapasitas personal. Kerjasama yang melibatkan dua negara tidaklah mudah karena terkait dengan perbedaan kepentingan dan prioritas nasional. Tidak bertemunya kepentingan nasional kedua negara, atau tidak merasa mendapatkan manfaat sesuai yang diharapkan, menyebabkan kerjasama tidak maksimal. Contohnya MOU antara untuk perguruan tinggi di level pemerintah belum terealisir karena tidak ada persamaan kepentingan antar pemerintah/departemen. Juga terdapat hambatan teknis yaitu pemegang kunci pendidikan di Filipina tidak tunggal seperti di Indonesia yang hanya dipegang Kemdikbud. Sementara di Filipina dibawah kendali berbagai institusi seperti Departemen of Education (DepEd), Commision on Higher Education (CHED) dan Technical Education dan Skill Development Authority (TESDA). Prosedur yang berbeda antar negara perlu dipahami benar sebelum MoU tersebut ditawarkan. Bahkan setelah MoU telah disetujui dan berakibat pada keharusan untuk melakukan implementasinya, mewujudkan kerjasama tersebut bisa terkendala. Dalam kasus kerjasama Indonesia - Filipina ini masih banyak MoU yang "tidur". Salah satunya dikarenakan tidak adanya persamaan minat di tingkat Universitas.

Fungsi moniroting Atdikbud tidak mudah. Atdikbud seringkali kesulitan mendata para penerima beasiswa warga negara Indonesia, khususnya yang tidak dibiayai oleh pemerintah Indonesia. Pemerintah Indonesia tidak pernah tahu sebenarnya jumlah keseluruhan warga negara atau siswa baik Indonesia dan Filipina yang belajar atau melakukan aktivitas terkait pendidikan. Masalah keuangan mengurangi kinerja Atdikbud dan menghambat program kerja. Penganggaran keuangan dan kegiatan diluar negeri menghadapi kendala tidak stabilnya rupiah, melemahnya kurs rupiah terhadap dolar. Keterlambatan pencairan keuangan bagi penerima bea siswa juga sering terjadi yang menghambat proses belajar. Dalam kondisi ini Atase dipaksa untuk mampu menyiasati kegiatan yang harus dilakukan dan dengan dana yang ada atau belum tersedia. 
Tantangan berikutnya adalah terkait dengan karakter yang dibutuhkan oleh seorang atase. Atase diharapkan mampu berkoordinasi dan berhubungan dengan berbagai level secara langsung. Dibutuhkan figur yang mempunyai keahlian Public Relations yang sesuai. Idealnya kapasitas dan kompetensi yang dimiliki oleh Atase adalah sesuai dengan kondisi wilayah tugas kerja. Contohnya seorang Atase Pendidikan dan Kebudayaan di Manila, tidak hanya mampu berbahasa Inggris, juga bahasa nasional Tagalog, serta memahami budaya dan kharakter setempat. Hal ini akan memudahkan Atase untuk bekerja khususnya dengan masyarakat lokal setempat.

\section{Simpulan}

Pemaparan tentang implementasi diplomasi soft power diatas semakin memperkuat signifikansi 'new diplomacy' atau 'neo diplomacy'. Inklusivitas aktor dalam proses diplomasi saat ini dibutuhkan. Diplomasi bukan hanya dilakukan oleh elit Kementrian Luar Negeri atau Kementrian Pendidikan dan Kebudayaan. Diplomasi yang berhasil harus mengikut sertakan publik atau stake holder secara aktif seperti penerima beasiswa, pelajar dan perguruan tinggi secara signifikan. Ada tuntutan untuk lebih memfokuskan pada isu yang lebih terkait dengan kebutuhan masyarakat dan non politik. Diplomasi karenanya kemudian harus berubah untuk dapat merespon aktor non state dan pengembangan sumber daya manusia menjadi isu utama dalam hubungan antar negara. Dalam diplomasi soft power tercapainya 'kepentingan dan keuntungan bersama' antar pelaku adalah suatu keharusan. Kemampuan untuk memahami kepentingan dan prioritas negara partner dalam proses diplomasi adalah sangat signifikan karena hakekatnya aktivitas ini merupakan trade off dari kepentingan antar pelaku. Dibutuhkan 'kedekatan yang sesungguhnya' bukan karena keterpaksaan, tapi ketertarikan dan penghargaan tentang kesamaan ide dan nilai yang dianut. Suatu bentuk kedekatan yang dipengaruhi oleh 'heart and mind'. Pendidikan dan pembelajaran budaya menjadi media untuk saling memahami dan menumbuhkan kedekatan tersebut.

Peranan Atdikbud dalam melaksanakan diplomas soft power adalah krusial. Lewat berbagai aktivitas seperti pemberian beasiswa, pendirian sekolah Indonesia, memfasilitasi program pertukaran dosen dan pelajar dan mahasiswa adalah signifikan dalam kerangka peningkatan hubungan antar negara serta pengaruh Indonesia di Filipina seklaigus perbaikan pendidikan di Indonesia guna meningkatkan daya saing Indonesia di level regional dan global. Kapasitas Atdikbud perlu ditingkatkan seperti kemampuan berkomunikasi dan beradaptasi agar program dapat berjalan maksimal mengingat nature dari diplomasi soft power yang tidak mudah dikontrol dan diprediksi. 
Terakhir, penelitian ini menguatkan relevansi diplomasi soft power dalam pelaksanaan kebijakan luar negeri RI saat ini. Penekanan untuk memprioritaskan pada unsur 'attractivenes' dari nilai-nilai ideologi, budaya, ilmu pengetahuan, keahlian, dan pendidikan adalah lebih relevan dalam meyakinkan publik diluar negeri tentang Indonesia dan mencapai tujuan nasional khususnya peningkatan sumberdaya manusia.

\section{Daftar Pustaka}

\section{Buku dan Artikel dalam Buku}

Berridge, G.R., 2005. Diplomacy: Theory and Practicde. New York: Palgrave.

Bull, Hedley, 1977. The Anarchical Society. New York Columbia University Press.

Dunne, Tim dan Brian C. Schmit, 2008. 'Realism' dalam John Baylis and Steve Smith, (eds.), The Globalization of World Politics, Oxford: Oxford University Press.

Feldman, Shai, 2003. Track II Diplomacy: Lesson from the Middle East. Cambridge: The MIT Press.

Freeman, Chas, 2006. The Diplomat's Diary, National Defense University Press.

Scheuerman, W.E., 2009. Hans Morgenthau. Realism and Beyond.

Cambridge: Polity Press

\section{Jurnal}

Fan, Ying, 2008. "Soft Power: Power of Attraction or Confusion." Place Branding and Public Diplomacy 4 (2): 147-158.

Gill, Bates dan Yanzhong Huang, 2006. "Sources and Limits of Chinese Soft Power." Survival 48(2): 145-156.

James, A.M., 1980. "Diplomacy and International Society", International Relations 6: 6.

Nye, Joseph S. Jr., 2004. "Soft Power and American Foreign Policy", Political Science Quarterly 119 (2).

Nye, Joseph, 1990. "Soft Power”. Foreign Policy 8o: 153-171.

Seng, Ding, 2010, "Analyzing Rising Power From the Perspective of Soft Power: A New Look at China's Rise to the Status Quo Power" Journal of Contemporary China 19 (64); 255-272.

Tatar, Justyna Szczudlik, 2010. "Soft Power in China's Foreign Policy" The Polish Quarterly of International Studies 3 (4). 


\section{Working Paper}

Asia News Monitor, 2011. Philippines/Indonesia: Aquino to Push for Advocacies that Will be Mutually Beneficial to Member Countries of ASEAN, 16 November.

Asia Pulse, 2011., Indonesia to Use Education as Cultural Diplomacy with US, 5 April.

Sen, Amartya, 2002. "Basic Education and Human Security" Background paper for the workshop on Basic Education and Human Security." Jointly orga-nized by the Commission on Human Security, UNICEF, the Harvard University, Kolkata, 2-4 January 2002.

Smith, Anthony L, 2000. "Strategic Centrality: Indonesia Changing Role in ASEAN”, Pacific Strategic Paper 10, Singapore Institute.

\section{Koran, Majalah dan Terbitan Berkala}

Bandoro, Bantarto, 2008. "Reassesing Indonesia Foreign Policy". Jakarta Post. 2 April.

Liddle, William, 1984. "Asia: Indonesia's Meat May Be Philippines Poison”, Wall Street Journal, Maret 12.

Yudhoyono, Bambang Susilo, 2005 'Revisiting Our Foreign Policy', The Jakarta Post, 2 Mei.

\section{Terbitan Resmi Pemerintah}

Kemdikbud, 2011. Naskah Akademik Penempatan Atase Pendidikan di KBRI Seoul, Korea Selatan.

Atase Pendidikan KBRI Manila, 2014. Laporan Kerjasama Bilateral Indonesia dan Filipina Bidang Pendidikan 2010-2013.

\section{Internet}

Ghose, Anindita, 2010. The Goverment Realizes the Value of Cultural Diplomacy [online] dalam http://www.livemint.com/Politics/qSiLCjnm8kkO15HIMSjY6N/The -govt-realizes-the-value-of-cultural-diplomacy.html. [diakses 17 Nopember 2015].

Republika, 2012. Kemdikbud Inisiasi Rumah Budaya di Beberapa Negara [online] dalam http://www.republika.co.id/berita/senggang/senibudaya/12/10/27/mckoyg-kemdikbud-inisiasi-rumah, diakses 27 Oktober 2015.

QS World University ranking, 2012 [online] dalam http://www.topuniversities.com/universityrankings/worlduniversity-rankings [diakses pada 17 Nopember 2015]. 